\title{
ANÁLISE DOS PORTAIS DE TRANSPARÊNCIA DE PEQUENOS MUNICÍPIOS DO PARANÁ
}

\author{
ANALYSIS OF TRANSPARENCY PORTAIS OF SMALL MUNICIPALITIES OF PARANÁ
}

Fabio Henrique Baraldi

Universidade Federal de Santa Catarina, SC, Brasil

E-mail: fabiohenriquebaraldi@hotmail.com

Altair Borgert

Universidade Federal de Santa Catarina, SC, Brasil

E-mail: altair@borgert.com.br

Valkyrie Vieira Fabre

Universidade do Estado de Santa Catarina, SC, Brasil E-mail: valkyrie.fabre@udesc.br

Recebido em: 08.06.2019 - Aceito em: 21.10.2019

DOI: http://dx.doi.org/10.5902/2526629238478

\section{RESUMO}

A accountability é abordada sob diversos aspectos, entre eles a transparência das informações, aspecto obrigatório perante a legislação brasileira. O objetivo desta pesquisa é verificar como está o atendimento às determinações da Lei de Acesso à Informação e da Lei da Transparência, por parte do poder executivo, em municípios com menos de 20.000 habitantes. Trata-se de uma pesquisa qualitativa descritiva que utilizou o levantamento documental para a coleta de dados. Analisou-se o conteúdo e o sítio eletrônico dos portais. Verificou-se, com isso, que as informações a respeito do sítio eletrônico, das despesas e das diárias são os mais divulgados, enquanto o bloco de transferências tem a menor divulgação. O percentual do ranking de transparência oscilou entre $11,67 \%$ e $91,67 \%$. A média de itens atendidos por portal foi de $67,34 \%$ do total de 60 obrigatórios. Estudos anteriores permeiam as discussões. Conclui-se que até mesmo os pequenos municípios não estão cumprindo todas as normas legais brasileiras, dando margem às críticas sobre os elementos da transparência pública. A falta de fiscalização e de punição podem ser as possíveis causas do não cumprimento integral da legislação.

PALAVRAS-CHAVE: Accountability; Transparência; Acesso à informação; Gestão pública; Municípios. 
ABSTRACT

Accountability is addressed in several aspects, including the transparency of information, which is mandatory under Brazilian law. The objective of this research is to verify how the compliance with the provisions of the Law on Access to Information and the Law on Transparency, by the executive branch, in municipalities with less than 20,000 inhabitants. It is a qualitative, descriptive research that used a documentary survey to collect data. The contents and electronic site of the portals were analyzed. It was verified that the information regarding the electronic site, expenses and daily, are the most publicized, while the block of transfers has the lowest disclosure. The percentage of the transparency ranking ranged from $11.67 \%$ to $91.67 \%$. The average of items served by portal was $67.34 \%$ of the total of 60 obligatory. Previous studies permeate the discussions. It is concluded that, even the small municipalities, are not complying with all Brazilian legal norms, giving rise to criticisms about the elements of public transparency. Lack of supervision and punishment may be the cause of non-compliance with legislation.

KEYWORDS: Accountability; Transparency; Access to information; Public administration; Counties.

\section{INTRODUÇÃO}

A administração pública vem passando por profundas mudanças, seja na gestão dos recursos públicos ou na gestão dos meios de divulgação das ações, essas mudanças são representadas nos modelos teóricos abordados pela literatura. O aparelhamento do Estado justifica-se pela prestação de serviços que visam à satisfação das necessidades coletivas, mas não só de prestação de serviços é composta a administração pública. Gerir o bem público também faz parte de suas atribuições e a responsabilidade do gestor está cada vez mais em pauta. Normas brasileiras estabelecem, então, não só a obrigatoriedade de uma boa gestão das finanças públicas, como também a ampla divulgação dos dados.

A accontability ainda não é a ideal, mas tem evoluído durante os governos. O termo inglês não tem tradução literal para o português, mas Mota (2006) explica que consiste na relação que obriga o gestor a prestar esclarecimentos sobre seus atos, passível de fiscalização e sujeito à sanção em caso de irregularidades. Dentre as dimensões da accountability, a transparência é a mais importante (Koppell, 2005; Mota, 2006).

Os meios de comunicação atuais têm proporcionado maior disseminação de informações. A gestão pública transparente permite informações à sociedade e colabora no controle das ações de seus governantes, com intuito de checar se 
os recursos públicos são usados como deveriam. De acordo com a Controladoria Geral da União (CGU, 2013), a transparência é um mecanismo indutor para que os gestores públicos ajam com responsabilidade.

No Brasil, a divulgação de dados sobre a gestão pública não é apenas recomendada, ela é uma obrigação legal, amparada na Lei Complementar $n^{\circ} 101$, de 4 de maio de 2000, Lei de Responsabilidade Fiscal (LRF); na Lei Complementar n. ${ }^{\circ}$ 131, de 27 de maio de 2009, Lei da Transparência (LT), e na Lei $n^{\circ}$ 12.527, de 18 de novembro de 2011, Lei de Acesso à Informação (LAI), as quais regulamentam a divulgação de informações prevista na Constituição da República de 1988.

Assim, a cada dia, o papel da transparência vem ganhando status de controle social, além da disponibilização dos dados na internet. A transparência ultrapassa a publicidade dos dados, pois facilita o acesso de qualquer cidadão às informações financeiras e aos serviços prestados pelos órgãos públicos, em tempo real, permitindo a análise e o acompanhamento por meio da fiscalização cidadã. Por isso, Raupp (2014) afirma que ela torna as relações entre o Estado e a sociedade civil mais democráticas.

Alguns estudos já analisaram a transparência das informações públicas, algo que no Brasil tem força legal, apontando que ela não é cumprida na íntegra. Raupp e Pinho (2013) afirmam que o conjunto dos portais eletrônicos de câmaras localizadas em municípios catarinenses demonstra a ausência da capacidade de viabilizar a construção das dimensões da accountability, visto que respondem a um requerimento, um impulso da modernidade expresso por um imperativo tecnológico dominante, mas que não contribuem para o desenvolvimento da transparência.

Staroscky, Nunes, Lyrio e Lunkes (2014), estudando os portais dos municípios que fazem parte da Secretaria de Desenvolvimento Regional (SDR) de Chapecó, no estado de Santa Catarina, utilizaram um método de pesquisa que se mostrou eficaz para estabelecer o nível de transparência dos portais municipais analisados. No entanto, os resultados demonstraram que os portais municipais estão, em termos de transparência, aquém do desejado e que compete aos gestores públicos incentivar a divulgação das informações além do que é solicitado.

Alguns estudos estão se preocupando com a questão da transparência nos portais dos municípios, sendo a maioria deles focados em municípios maiores, tem encontrado resultados que não condizem com o estabelecido pela norma legal (Raupp \& Pinho, 2016). No Estado do Paraná, composto por 399 cidades (IBGE, 2017), foi realizado um levantamento nos municípios com mais de 50.000 habitantes, por Souza e Peixe (2017), confirmando que nem tudo que é obrigató- 
rio está sendo divulgado. No entanto, tal levantamento casou a dúvida sobre a generalização dos resultados, uma vez que a pesquisa não abrangeu os municípios menores, que são a maioria.

Assim, esta pesquisa tem por objetivo verificar como está o atendimento às determinações da Lei de Acesso à Informação e da Lei da Transparência, por parte do poder executivo, em municípios com menos de 20.000 habitantes.

A pesquisa foi realizada no estado do Paraná e contou com uma amostra de 32 pequenos municípios, localizados na região noroeste. Procurou-se analisar os portais de transparência quanto ao conteúdo e quanto ao sítio eletrônico, além de consolidar as informações levantadas, a fim de gerar um ranking classificatório da transparência dos municípios.

Nos municípios brasileiros, não existe um sistema informatizado padrão para gerar e divulgar as informações necessárias. Assim, cada um deles contrata seu prestador de serviços e, no caso de municípios pequenos, alguns se unem para realizar licitações intermunicipais, a fim de conseguirem menor preço e meIhor assistência técnica.

Fabre e Bonfante (2018) apontam que nos últimos 10 anos tem aumentado o número de pesquisas sobre administração e contabilidade pública. Um exemplo disso é que, no Brasil, 34\% dessas pesquisas foram direcionadas ao governo municipal, sendo a maioria delas realizada com dados de grandes centros populacionais e econômicos. Ainda há, porém, muito a explorar em relação aos pequenos municípios brasileiros, pois generalizar pesquisas sem considerar a parcela desses municípios, que no Brasil são a maioria, traz uma limitação considerável aos resultados.

Esta pesquisa, portanto, contribui para a ampliação do arcabouço teórico, em relação à transparência pública, por tratar de informações de pequenos municípios brasileiros ainda pouco explorados nessa temática. É relevante, pois aborda a divulgação nos portais públicos como parte da transparência que se espera dos governos e como uma das dimensões do conceito maior de accountability.

\section{REFERENCIAL TEÓRICO}

Paludo (2010) afirma que exercer a accountability é a contrapartida do poder de tomar decisões e de utilizar recursos públicos, refere-se à prestação de contas. Ela pode ser conceituada sob diversas dimensões que se relacionam, direta ou indiretamente, ao fornecimento de informações por parte de um órgão aos seus interessados (Amaral, 2007). Na esfera pública, possibilita o aprimoramento das 
instituições no que diz respeito ao desempenho dos programas de governo, de transparência e de responsabilidade perante a sociedade, enquanto, na esfera privada, ela não se condiciona aos cidadãos e ao controle social, no entanto, sofre influência representativa deste grupo (Abrucio \& Loureiro, 2006).

A accountability, na administração pública, segundo Rocha (2011), é tratada dentro de três modelos teóricos: o modelo clássico ou da Administração Pública Tradicional (APT), o modelo da Nova Gestão Pública (NGP) e o modelo do Novo Serviço Público (NSP). O modelo APT foca no poder do Estado, representado pelo líder eleito, partindo de um pensamento burocrata, em que as normas legais regem os processos de gestão e há fiscalização externa sobre isso (Behn, 1998). O modelo NGP foca no poder do mercado, no qual o Estado deve atender as necessidades dos clientes (cidadãos) mais como regulador do que como prestador dos serviços, reduzindo custos e privatizando serviços (Barzelau, 2001). O modelo NSP foca nas pessoas, sejam elas os servidores públicos ou os cidadãos, de modo a priorizar o interesse público e fortalecer a democracia, reconhecendo a accountability como algo importante, difícil e necessário à gestão pública (Denhardt \& Denhardt, 2002).

Apesar de abordagens diferentes, todos os modelos teóricos remetem ao déficit de accountability. Nesse sentido, a falta de transparência permeia sempre as discussões (Rocha, 2011), por ser a mais importante categoria da accountability, um requisito chave para todas as outras dimensões (Koppell, 2005).

Segundo Mota (2006), a falta de transparência tem sido o principal gargalo da accountability dos governos e, apesar dos investimentos maciços em tecnologia da informação realizados pelo governo federal e da enorme quantidade de informações disponibilizadas nos portais públicos, no Brasil não é diferente.

Nos Estados Unidos da América, a busca pela accountability levou ao aumento das informações divulgadas por entes da administração pública, sobretudo com o objetivo de obter legitimidade quanto aos cidadãos (Icerman \& Sinason, 1996). Segundo os autores, a transparência aumentou a capacidade de acompanhamento dos programas e das informações divulgadas, ao assegurar que as políticas definidas sejam cumpridas, porém, permanece a assimetria entre as informações divulgadas pelo governo e as que os cidadãos esperam.

No Brasil, os debates em torno da transparência da gestão pública se reportam à Lei de Responsabilidade Fiscal. Exige-se transparência e ampla divulgação, inclusive em meios eletrônicos de acesso público, dos instrumentos de planejamento orçamentário, das prestações de contas e seus respectivos pareceres além 
de outros relatórios concernentes à gestão fiscal (LRF, 2000). Contudo, a grande influência da internet é considerada um dos principais e mais dominantes meios de comunicação da atualidade, uma vez que estimula o controle social.

Segundo Platt, Cruz, Ensslin e Ensllin (2007), a transparência pode ser formada por três elementos ou dimensões: publicidade, compreensibilidade e utilidade para decisão. Na publicidade, é importante que a divulgação e o acesso estejam disponíveis para qualquer cidadão a qualquer hora. Considera-se compreensibilidade a linguagem e a apresentação de forma clara e acessível. A utilidade para decisão requer informações relevantes e confiáveis. Assim, não basta apenas disponibilizar dados na internet, pois a publicação é apenas um dos elementos da transparência.

Esta pesquisa trata, especificamente, da evidenciação de informações obrigatórias e de caráter normativo no Brasil. O aumento na publicidade das informações ganhou notoriedade depois da criação LRF, que estabelece normas de finanças públicas voltadas à responsabilidade na gestão fiscal em busca do equilíbrio das contas públicas e da prevenção de riscos e de desvios. Em relação à divulgação dos dados, destaca-se o capítulo IX da LRF sobre transparência, controle e fiscalização. A Lei da Transparência (LT) regulamentou e garantiu a todos o acesso às informações dos atos praticados pela administração pública, tais como licitações, despesas, gastos com folhas de pagamento, contratos, obras, transferências, entre outros. Para isso, faz-se necessário que o órgão público mantenha em seu site um portal de fácil acesso, contendo todas as informações que a lei exige. Após doze anos da LRF, entrou em vigor a Lei de Acesso à Informação (LAI), com a finalidade de regulamentar o acesso à informação, previsto no art. $5^{\circ}$, XXXIII, no art. $37, \S 3^{\circ}$, II e no art. 216 , $2^{\circ}$, da Constituição da República de 1988, que tratam respectivamente de direitos e de garantias fundamentais de natureza individual e coletiva.

Nessa perspectiva, estudos anteriores relacionados ao tema e que utilizaram amostras brasileiras de portais de transparência são relevantes para este estudo. Um crescente número de publicações procurou avaliar esses portais dos entes públicos. Diversos estudos avaliaram portais de prefeituras municipais (Costa, Leite \& Campos, 2014; Raupp, Abreu \& Silva, 2014; Staroscky et al., 2014; Figueiredo \& Gazoni, 2016; Fabre, Bornia \& Borgert, 2017), de governos estaduais (Sales, 2012; Resende \& Nassif, 2015; Abdala \& Torres, 2016) e do Governo Federal (Nazário, Silva \& Rover, 2012; Prado, Ribeiro \& Diniz, 2012; Freire, 2014). Outros se ativeram aos portais do Poder Judiciário (Melo \& Gomes, 2016) e do Po- 
der Legislativo (Raupp \& Pinho, 2013; Raupp, 2014; Raupp \& Pinho, 2014; Raupp \& Pinho, 2016; Fabre, Rosa \& Bornia, 2016) e, também, de municípios com mais de 50.000 habitantes do Paraná (Souza \& Peixe, 2017).

Os resultados das pesquisas no Brasil revelam um Estado ainda incipiente no uso dos recursos tecnológicos de comunicação para divulgação de informações acerca da atuação governamental, evidenciando a forte presença de uma estrutura autoritária, centralizadora e resistente à participação popular típica da APT. Esses estudos convergem à literatura internacional que mostra resultados modestos na utilização dos recursos tecnológicos de comunicação no setor público (Pinho, 2006).

Ao pesquisar as câmaras de vereadores nas capitais brasileiras, com base na teoria da evidenciação (disclosure), aplicada aos portais oficiais, Fabre et al. (2016) comprovaram a falta de transparência dos atos do legislativo e a insignificante promoção da participação popular, confirmando as motivações do clamor social por maior transparência, accountability e evidenciação dos atos praticados pelos gestores públicos brasileiros. O poder legislativo tem se configurado como um exemplo de falta de transparência e de punição, pois a divulgação de informações não condiz com as normas legais brasileiras (Raupp \& Pinho, 2013; Raupp, 2014; Raupp \& Pinho, 2014; Raupp \& Pinho, 2016).

Quanto ao envolvimento da sociedade na fiscalização da gestão pública, Monteiro, Lacerda e Luz (2004) constataram que os entrevistados não compreendem claramente o processo de transparência e encontram dificuldades para o envolvimento social e, mesmo após a divulgação das informações a respeito da atuação governamental, muitos não conseguem encontrar as informações oficiais.

Raupp e Pinho (2014) afirmam que a prestação de contas do poder executivo de alguns municípios de Santa Catarina é insuficiente. Os autores revelam que apenas $24 \%$ dos municípios cumprem a legislação e que os portais da amostra são utilizados apenas como mural eletrônico e não como promotores de incentivo ao exercício da cidadania.

Souza e Peixe (2017) verificaram, utilizando seu próprio protocolo de observações para investigar os portais de transparência dos municípios paranaenses com mais de 50.000 habitantes, que não ocorre cumprimento pleno de determinações legais básicas e que há espaço para aperfeiçoamento do instrumento.

Fabre (2017) propôs um instrumento de coleta, utilizando a teoria da evidenciação (quanto ao disclosure obrigatório), a accountability (quanto à prestação de contas dos gestores municipais) e a transparência (quanto à divulgação das 
informações e os interesses dos cidadãos) para medir a divulgação das informações obrigatórias. Ao testar esse instrumento nos municípios catarinenses, os autores Fabre, Bornia e Borgert (2017) concluíram que o instrumento mede o traço latente a que se propõe. Além disso, os resultados dos indicadores de disclosure obrigatórios calculados revelaram que nenhum município cumpriu a totalidade das obrigações legais de divulgação.

Assim, alguns estudos já confirmaram que a norma legal não é cumprida na íntegra, mas as amostras utilizadas são de órgãos públicos com estruturas maiores. Cabe ainda, portanto, aprofundar essas conclusões em municípios pequenos, os quais são o foco desta pesquisa.

\section{MÉTODO DE PESQUISA}

O propósito desta pesquisa é verificar como está o atendimento às determinações da Lei de Acesso à Informação e da Lei da Transparência, por parte do poder executivo, em municípios com menos de 20.000 habitantes. A pesquisa foi realizada com municípios do Paraná, que conta com 399 cidades, das quais 305 estão nesta faixa populacional. Optou-se por uma amostra intencional, composta pelos 32 municípios que fazem parte da Associação dos Municípios Entre Rios, noroeste do Paraná (AMERIOS, 2017). A amostra representa $10 \%$ da população desta pesquisa.

A pesquisa e a identificação dos portais de transparência dos municípios aconteceram através do site do Google (2019), sendo a pesquisa realizada com a seguinte expressão padrão: "Prefeitura Municipal de [nome do município]". Cruz, Silva e Santos (2009) utilizaram a mesma expressão para realizar sua pesquisa. Paiva e Zuccolotto (2009) enfatizam que essa seria a forma com que um cidadão que não possui conhecimento técnico realizaria a pesquisa para encontrar o site do seu município. O Quadro 1 apresenta a relação dos municípios e seus respectivos sítios eletrônicos. 
Quadro 1 - Municípios Pesquisados

\begin{tabular}{|c|c|c|c|}
\hline Município & Endereço do portal & Município & Endereço do portal \\
\hline Alto Paraíso & www.altoparaiso.pr.gov.br & Japurá & www.japura.pr.gov.br \\
\hline Alto Piquiri & www.altopiquiri.pr.gov.br & Jussara & www.jussara.pr.gov.br \\
\hline Altônia & www.altonia.pr.gov.br & $\begin{array}{l}\text { Maria } \\
\text { Helena }\end{array}$ & www.mariahelena.pr.gov.br \\
\hline $\begin{array}{l}\text { Brasilândia } \\
\text { do Sul }\end{array}$ & www.brasilandiadosul.pr.gov.br & Mariluz & www.mariluz.pr.gov.br \\
\hline $\begin{array}{l}\text { Cafezal do } \\
\text { Sul }\end{array}$ & www.cafezaldosul.pr.gov.br & $\begin{array}{l}\text { Nova } \\
\text { Olímpia }\end{array}$ & www.novaolimpia.gov.br \\
\hline Cianorte & www.cianorte.pr.gov.br & Perobal & www.perobal.pr.gov.br \\
\hline $\begin{array}{l}\text { Cidade } \\
\text { Gaúcha }\end{array}$ & www.cidadegaucha.pr.gov.br & Pérola & www.perola.pr.gov.br \\
\hline $\begin{array}{l}\text { Cruzeiro do } \\
\text { Oeste }\end{array}$ & www.cruzeirodooeste.pr.gov.br & Rondon & www.rondon.pr.gov.br \\
\hline Douradina & www.douradina.pr.gov.br & $\begin{array}{c}\text { São } \\
\text { Jorge do } \\
\text { Patrocínio }\end{array}$ & www.sjpatrocinio.pr.gov.br \\
\hline $\begin{array}{l}\text { Esperança } \\
\text { Nova }\end{array}$ & www.esperancanova.pr.gov.br & $\begin{array}{c}\text { São } \\
\text { Manoel do } \\
\text { Paraná }\end{array}$ & $\begin{array}{l}\text { www.saomanoeldoparana. } \\
\text { pr.gov.br }\end{array}$ \\
\hline $\begin{array}{l}\text { Francisco } \\
\text { Alves }\end{array}$ & www.franciscoalves.pr.gov.br & São Tomé & www.saotome.pr.gov.br \\
\hline $\begin{array}{l}\text { Guaporema } \\
\text { Icaraíma }\end{array}$ & $\begin{array}{l}\text { www.guaporema.pr.gov.br } \\
\text { www.icaraima.pr.gov.br }\end{array}$ & $\begin{array}{l}\text { Tapejara } \\
\text { Tapira }\end{array}$ & $\begin{array}{l}\text { www.tapejara.pr.gov.br } \\
\text { www.tapira.pr.gov.br }\end{array}$ \\
\hline Indianópolis & www.indianopolis.pr.gov.br & $\begin{array}{l}\text { Tuneiras } \\
\text { do Oeste }\end{array}$ & $\begin{array}{l}\text { www.tuneirasdooeste. } \\
\text { pr.gov.br }\end{array}$ \\
\hline Iporã & www.ipora.pr.gov.br & $\begin{array}{l}\text { Umuarama } \\
\text { (Sede) }\end{array}$ & www.umuarama.pr.gov.br \\
\hline Ivaté & www.ivate.pr.gov.br & Xambrê & www.xambre.pr.gov.br \\
\hline
\end{tabular}

Durante a pesquisa, os sites que estavam fora do ar, por apresentar problemas de acesso ou estar "em construção", foram acessados três vezes com o propósito de assegurar que todos os municípios apresentassem portais de transparência no período em que foi realizada a coleta de dados. Então, foi realizada uma navegação por todos os itens dos menus em busca de informações, seguindo o protocolo de observação. A coleta de dados foi realizada em outubro e novembro de 2017.

Trata-se de uma pesquisa com abordagem qualitativa, objetivos descritivos e procedimentos documentais, mais especificamente de levantamento de dados por observação em portais oficiais de governos municipais.

Autores como Costa et al. (2014), Raupp et al. (2014), Staroscky et al. (2014), Fegueiredo e Gazoni (2016) e Fabre et al. (2017) testaram instrumentos de pesquisa já desenvolvidos anteriormente. Para essa pesquisa foi utilizado o 
"Formulário de Observação de Disclosure Obrigatório para Portais de Transparência" de Fabre (2017). A escolha foi embasada nos testes estatísticos, já realizados no instrumento por Fabre et al. (2017), que revelaram que tal instrumento mede o traço latente para o qual foi desenvolvido (a transparência dos portais públicos), além de ser o dispositivo mais atualizado em relação à legislação vigente no Brasil sobre obrigações de divulgação nos portais públicos de transparência. A Figura 1 apresenta o formulário utilizado nesta pesquisa.

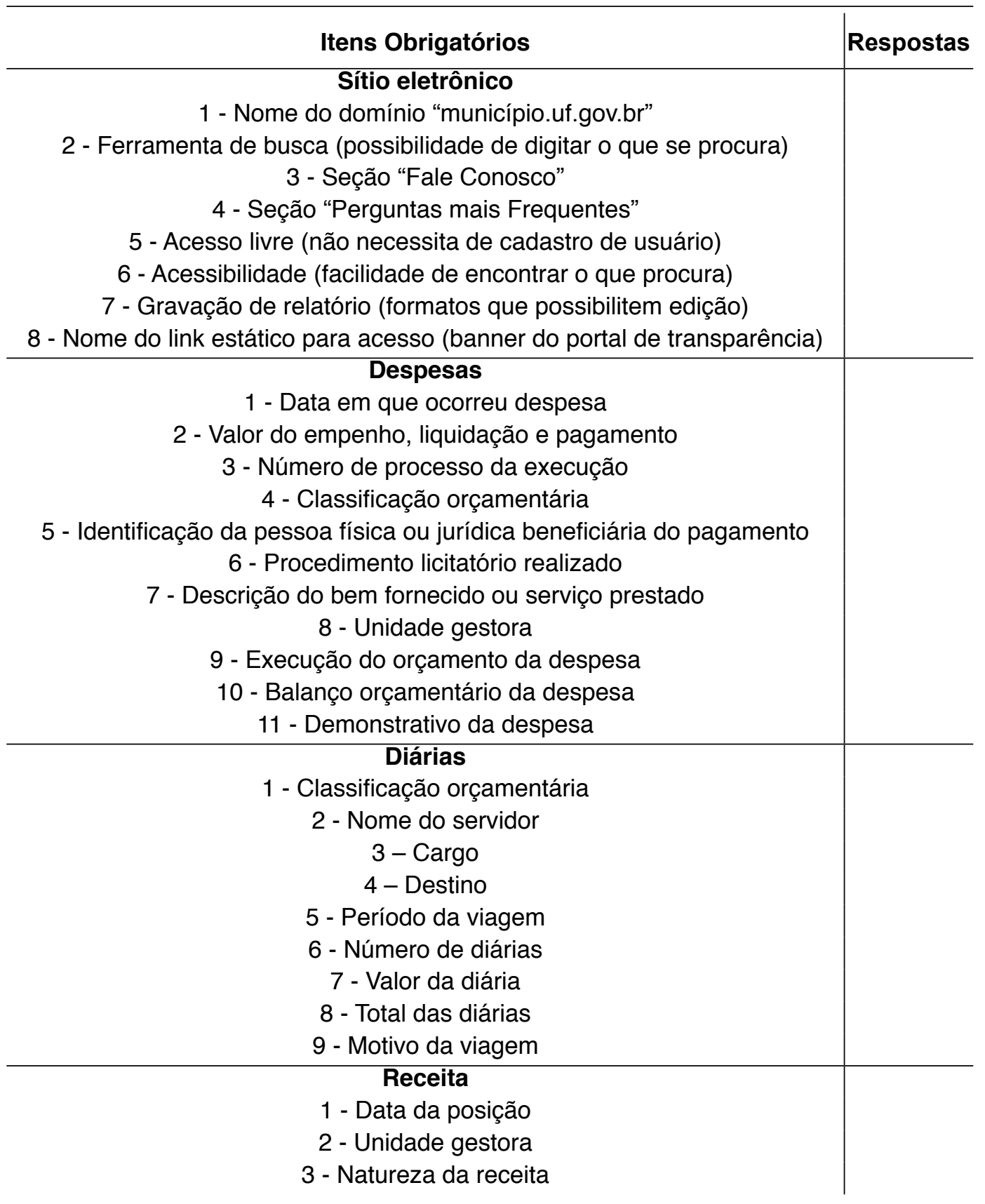




\begin{tabular}{|c|}
\hline $\begin{array}{c}4 \text { - Valor da previsão } \\
5 \text { - Valor do lançamento } \\
6 \text { - Valor da arrecadação } \\
7 \text { - Execução do orçamento da receita } \\
8 \text { - Balanço orçamentário da receita } \\
9 \text { - Demonstrativo da receita }\end{array}$ \\
\hline $\begin{array}{c}\text { Informações Financeiras } \\
1 \text { - Plano Plurianual - PPA } \\
2 \text { - Lei de Diretrizes Orçamentárias - LDO } \\
3 \text { - Lei Orçamentária Anual - LOA } \\
4 \text { - Relatório Resumido da Execução Orçamentária } \\
5 \text { - Relatório de Gestão Fiscal } \\
6 \text { - Balanço anual do exercício }\end{array}$ \\
\hline $\begin{array}{c}\text { Licitações } \\
1 \text { - Informações dos procedimentos licitatórios } \\
2 \text { - Contratos } \\
3 \text { - Compras Diretas } \\
4 \text { - Convênios }\end{array}$ \\
\hline $\begin{array}{c}\text { Transferências (recebidas) } \\
1 \text { - Transferências da União } \\
1.1 \text { - Valores entregues pela união } \\
1.2 \text { - Valor arrecado no período e até o período } \\
1.3 \text { - Mês de arrecadação } \\
2 \text { - Transferências do Estado } \\
2.1 \text { - Valores entregues pelo Estado } \\
2.2 \text { - Valor arrecado no período e até o período } \\
2.3 \text { - Mês de arrecadação }\end{array}$ \\
\hline $\begin{array}{c}\text { Remuneração dos Servidores } \\
\text { 1- Remuneração } \\
2 \text { - Subsídios recebidos } \\
3 \text { - Graduação } \\
4 \text { - Função } \\
5 \text { - Auxílios } \\
6 \text { - Proventos de aposentadoria / Pensões }\end{array}$ \\
\hline $\begin{array}{l}\text { TOTAL } \\
\end{array}$ \\
\hline
\end{tabular}

Figura 1 - Formulário de observação: disclosure obrigatório de portais de transparência pública.

Fonte: Fabre (2017).

A Figura 1 elenca 60 itens, todos extraídos das normas vigentes que consideram essas informações obrigatórias. Oito blocos principais compõem o instrumento de pesquisa, sendo eles: sítio eletrônico (8 itens foram pesquisados), despesas (11 itens), diárias (9 itens), receita (9 itens), informações financeiras (5 itens), licitações (4 itens), transferências (8 itens) e remuneração dos servi- 
dores (6 itens). Para cada bloco é calculado um escore (escala de 0 a 2: não atende $=0$, atende parcialmente $=1$, atende $=2$; a soma de todos define o escore total do município pesquisado (Fabre, 2017). Nesta pesquisa, a escala foi adaptada para: não atende $=0$ e atende $=1$.

\section{APRESENTAÇÃO E DISCUSSÃO DOS RESULTADOS}

Para melhor identificação, os resultados da pesquisa foram subdivididos em duas partes. A primeira apresenta os resultados de cada item avaliado, enquanto a segunda parte dispõe o ranking dos municípios conforme seu grau de atendimento aos itens pesquisados.

Essa avaliação foi realizada a partir da verificação do cumprimento, ou não, dos itens. Assim, os percentuais apresentados nos resultados correspondem ao grau de cumprimento desses itens por parte dos portais de transparência dos municípios.

\subsection{Conteúdos dos portais}

Conforme a Tabela 1, em média $85,93 \%$ dos municípios atendem os itens referentes ao sítio eletrônico. Quanto à divulgação de dados acerca da execução orçamentária, as informações sobre as despesas são mais divulgadas do que as receitas.

Quanto à receita, os itens com maiores frequências de atendimento à legislação são o valor da arrecadação e a data da posição da receita (ambos 93\%). Informações sobre execução do orçamento da despesa são as menos frequentes (em $62 \%$ dos casos).

Tabela 1 - Avaliação do conteúdo do portal disponibilizado pelos municípios

\begin{tabular}{|c|c|c|c|}
\hline Item & $\begin{array}{r}\text { Assunto } \\
\end{array}$ & $\begin{array}{l}\text { Número de } \\
\text { Municípios }^{*}\end{array}$ & $\begin{array}{c}\text { \% de } \\
\text { Municípios }^{*}\end{array}$ \\
\hline \multicolumn{2}{|c|}{ Itens referente ao sítio eletrônico } & 32 & 85,93 \\
\hline 1 & Nome do domínio "município.uf.gov.br" & 32 & 100,00 \\
\hline 2 & Ferramenta de busca & 32 & 100,00 \\
\hline 3 & Seção “Fale Conosco" & 25 & 78,12 \\
\hline 4 & Seção "Perguntas mais Frequentes" & 8 & 25,00 \\
\hline 5 & Acesso livre & 32 & 100,00 \\
\hline 6 & Acessibilidade & 30 & 93,75 \\
\hline 7 & Gravação de relatório & 30 & 93,75 \\
\hline 8 & Nome do link estático para acesso & 31 & 96,87 \\
\hline \multicolumn{2}{|c|}{ Itens referente ao conteúdo das despesas } & 32 & 85,22 \\
\hline 9 & Data em que ocorreu despesa & 31 & 96,87 \\
\hline 10 & $\begin{array}{c}\text { Valor do empenho, liquidação e } \\
\text { pagamento. }\end{array}$ & 31 & 96,87 \\
\hline
\end{tabular}




\begin{tabular}{|c|c|c|c|}
\hline 11 & Número de processo da execução & 31 & 96,87 \\
\hline 12 & Classificação orçamentária & 27 & 84,37 \\
\hline 13 & $\begin{array}{l}\text { Identificação da pessoa física/jurídica } \\
\text { beneficiária }\end{array}$ & 31 & 96,87 \\
\hline 14 & Procedimento licitatório realizado & 31 & 96,87 \\
\hline 15 & $\begin{array}{c}\text { Descrição do bem fornecido ou serviço } \\
\text { prestado }\end{array}$ & 31 & 96,87 \\
\hline 16 & Unidade gestora & 30 & 93,75 \\
\hline 17 & Execução do orçamento da despesa & 20 & 62,50 \\
\hline 18 & Balanço orçamentário da despesa & 18 & 56,25 \\
\hline 19 & Demonstrativo da despesa & 19 & 59,37 \\
\hline \multicolumn{2}{|r|}{ Itens referentes às diárias } & 32 & 84,72 \\
\hline 20 & Classificação orçamentária & 19 & 59,37 \\
\hline 21 & Nome do servidor & 29 & 90,62 \\
\hline 22 & Cargo & 27 & 84,37 \\
\hline 23 & Destino & 29 & 90,62 \\
\hline 24 & Período da viagem & 29 & 90,62 \\
\hline 25 & Número de diárias & 27 & 84,37 \\
\hline 26 & Valor da diária & 26 & 81,25 \\
\hline 27 & Total das diárias & 29 & 90,62 \\
\hline 28 & Motivo da viagem & 29 & 90,62 \\
\hline \multicolumn{2}{|r|}{ Itens referentes às receitas } & 32 & 67,01 \\
\hline 29 & Data da posição & 30 & 93,75 \\
\hline 30 & Unidade gestora & 27 & 84,37 \\
\hline 31 & Natureza da receita & 28 & 87,50 \\
\hline 32 & Valor da previsão & 6 & 18,75 \\
\hline 33 & Valor do lançamento & 24 & 75,00 \\
\hline 34 & Valor da arrecadação & 30 & 93,75 \\
\hline 35 & Execução do orçamento da receita & 16 & 50,00 \\
\hline 36 & Balanço orçamentário da receita & 16 & 50,00 \\
\hline 37 & Demonstrativo da receita & 16 & 50,00 \\
\hline \multicolumn{2}{|r|}{ Itens referentes às informações financeiras } & 32 & 68,12 \\
\hline 38 & Plano Plurianual - PPA & 24 & 75,00 \\
\hline 39 & Lei de Diretrizes Orçamentárias - LDO & 24 & 75,00 \\
\hline 40 & $\begin{array}{c}\text { Relatório Resumido da Execução } \\
\text { Orçamentária }\end{array}$ & 23 & 71,87 \\
\hline 41 & Relatório de Gestão Fiscal & 21 & 65,62 \\
\hline 42 & Balanço anual do exercício & 17 & 53,12 \\
\hline \multicolumn{2}{|r|}{ Itens referentes às licitações } & 32 & 61,71 \\
\hline 43 & $\begin{array}{c}\text { Informações dos procedimentos } \\
\text { licitatórios }\end{array}$ & 30 & 93,75 \\
\hline 44 & Contratos & 29 & 90,62 \\
\hline 45 & Compras Diretas & 7 & 21,87 \\
\hline 46 & Convênios & 13 & 40,62 \\
\hline \multicolumn{2}{|r|}{ Itens referentes às transferências } & 32 & 34,37 \\
\hline 47 & 1 - Transferências da União & 11 & 34,37 \\
\hline 48 & 1.1 - Valores entregues pela união & 11 & 34,37 \\
\hline
\end{tabular}




\begin{tabular}{|c|c|c|c|}
\hline 49 & $\begin{array}{l}1.2 \text { - Valor arrecado no período e até o } \\
\text { período }\end{array}$ & 11 & 34,37 \\
\hline 50 & 1.3 - Mês de arrecadação & 11 & 34,37 \\
\hline 51 & 2 - Transferências do Estados & 11 & 34,37 \\
\hline 52 & 2.1 - Valores entregues pelo Estado & 11 & 34,37 \\
\hline 53 & $\begin{array}{l}2.2 \text { - Valor arrecado no período e até o } \\
\text { período }\end{array}$ & 11 & 34,37 \\
\hline 54 & 2.3 - Mês de arrecadação & 11 & 34,37 \\
\hline \multicolumn{2}{|c|}{ Itens referentes aos servidores } & 32 & $\mathbf{7 4 , 3 7}$ \\
\hline 55 & Remuneração & 30 & 93,75 \\
\hline 56 & Subsídios recebidos & 30 & 93,75 \\
\hline 57 & Graduação & 0 & 0 \\
\hline 58 & Função & 28 & 87,50 \\
\hline 59 & Auxílios & 20 & 62,50 \\
\hline 60 & Proventos de aposentadoria / Pensões & 11 & 34,37 \\
\hline
\end{tabular}

No grupo de itens de informações financeiras, $68,12 \%$ dos municípios divulgam a informação. Os mais frequentes são o Plano Plurianual (PPA) e a Lei de Diretrizes Orçamentárias (LDO), ambos em 75\% dos casos, e os relatórios de gestão fiscal, em $71 \%$ dos casos. Por outro lado, apenas $53 \%$ dos municípios divulgam o balanço anual do exercício.

Observa-se que, mesmo sendo obrigatório, o grau de instrução dos servidores (Graduação) não é divulgado pelos municípios (0\%). Merecem destaque três itens que são cumpridos em todos os portais pesquisados (100\%): o nome do domínio "município.uf.gov.br", a ferramenta de busca e o acesso livre.

Dentre os municípios pesquisados, todos divulgam informações relativas ao grupo de itens de despesas, exceto o portal de Ivaté, que somente apresenta relatório de despesas segundo as categorias econômicas.

Os resultados evidenciam que, apesar de ser obrigatória, os municípios não realizam a divulgação de todas as informações, ou seja, a divulgação de todos os itens elencados na Tabela 1. Pesquisas anteriores, como as de Amaral (2007), Raupp (2014), Costa et al. (2014) e Fabre et al. (2017), que observaram o poder executivo de municípios maiores, já apontaram que as normas legais voltadas à divulgação de dados nos portais não estão sendo cumpridas em sua totalidade. Esta pesquisa, que foi realizada em municípios pequenos, também confirmou esse fato, levando ao descrédito quanto a aplicação e a fiscalização das normas jurídicas brasileiras.

$\mathrm{Na}$ Tabela 1 ficou evidente que as informações a respeito do sítio eletrôni- 
co $(85,93 \%)$, das despesas $(85,22 \%)$ e das diárias $(84,72 \%)$ obtiveram melhores resultados em comparação aos outros blocos consultados. O bloco de transferências teve o menor percentual de atendimento durante a pesquisa $(34,37 \%)$.

No estudo de Fabre et al. (2017), as informações a respeito do bloco de sítio eletrônico $(93,75 \%)$, de despesas $(80,40 \%)$ e de licitações $(84,05 \%)$ obtiveram melhores resultados em comparação aos outros blocos consultados, ficando o bloco de transferências $(45,25 \%)$ e de remuneração de servidores $(45,97 \%)$ com os menores percentuais de atendimento durante a pesquisa.

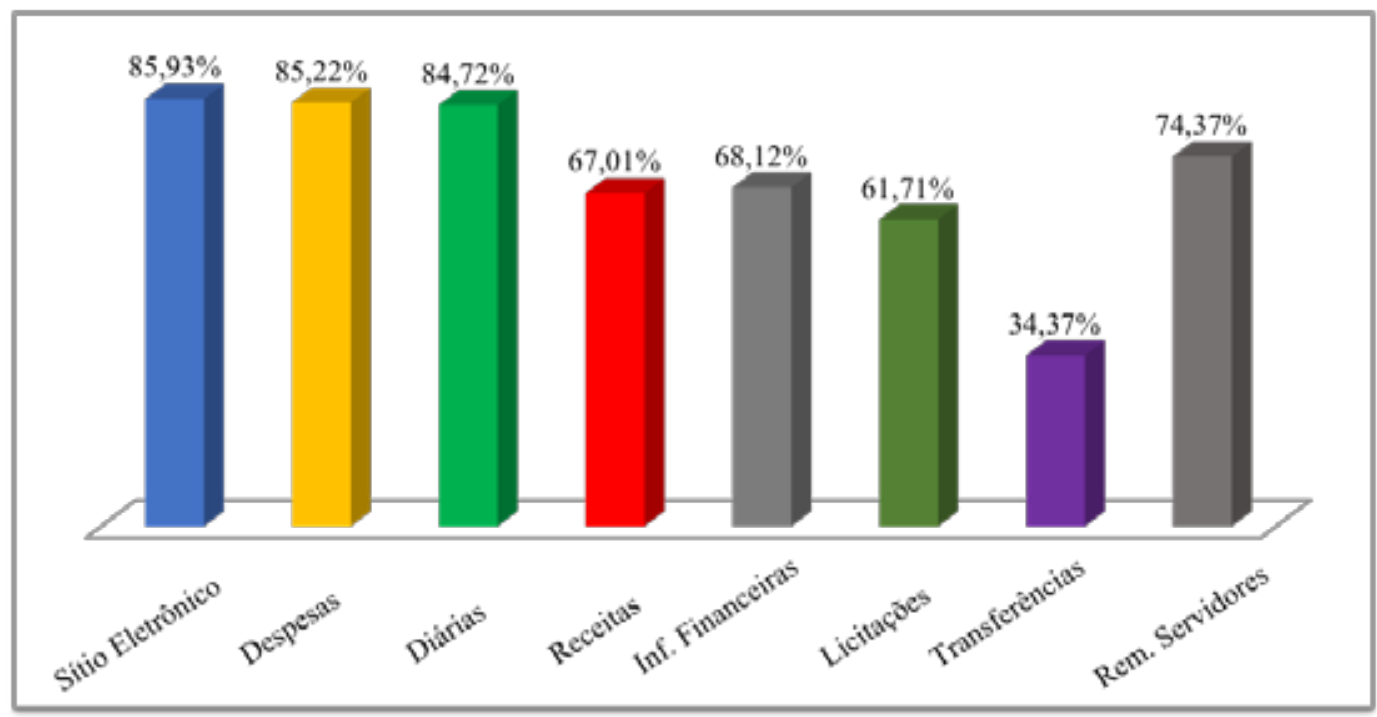

Figura 2 - Comparativo dos blocos de transparência.

Fonte: Dados da pesquisa (2017).

A pesquisa realizada por Souza e Peixe (2017), em que utilizaram um protocolo de observação com 53 itens para avaliação dos portais, diferente do aplicado neste artigo, resultou na maior divulgação de receitas (90\%), de despesas (98\%) e de sítio eletrônico (77\%), em comparação aos outros blocos consultados. As licitações $(71 \%)$ e as informações financeiras $(70 \%)$ foram os itens menos atendidos naquela pesquisa.

\subsection{Ranking dos portais de transparência}

$\mathrm{Na}$ Tabela 4 foram relacionados os portais em ordem decrescente de acordo com o cumprimento do total dos grupos de itens avaliados. Os três portais que obtiveram melhores classificações foram os de Jussara, Mariluz e Umuarama (todos com 91,67\%). Por outro lado, ficaram com menores percentuais de cumprimento dos itens avaliados os portais de transparência de Rondon (41,67\%), Iporã 
$(26,67 \%)$ e Ivaté $(11,67 \%)$.

Nessa avaliação geral dos portais, a média de itens atendidos por portal foi de 40 , que corresponde a $67,34 \%$ do total de 60 itens obrigatórios, oscilando entre os extremos de $11,67 \%$ e $91,67 \%$. Esses resultados corroboram com os encontrados por Fabre et al. (2017), que utilizaram o mesmo procedimento de pesquisa para analisar os municípios de Santa Catarina e afirmaram que em média apenas $67 \%$ dos itens foram disponibilizados pelos municípios nos portais.

Tabela 2 - Ranking dos portais quanto ao cumprimento geral dos itens avaliados

\begin{tabular}{|c|c|c|}
\hline Município & $\mathrm{N}^{\circ}$ de itens atendidos & $\%$ de cumprimento \\
\hline Jussara & 55 & 91,67 \\
\hline Mariluz & 55 & 91,67 \\
\hline Umuarama (sede) & 55 & 91,67 \\
\hline Pérola & 52 & 86,67 \\
\hline Indianópolis & 51 & 85,00 \\
\hline Francisco Alves & 49 & 81,67 \\
\hline Maria Helena & 49 & 81,67 \\
\hline São Jorge do Patrocínio & 49 & 81,67 \\
\hline Japurá & 46 & 76,67 \\
\hline Tapejara & 46 & 76,67 \\
\hline Tapira & 46 & 76,67 \\
\hline Xambrê & 45 & 75,00 \\
\hline Nova Olímpia & 44 & 73,33 \\
\hline Altônia & 43 & 71,67 \\
\hline Douradina & 43 & 71,67 \\
\hline Tuneiras do Oeste & 42 & 70,00 \\
\hline Brasilândia do Sul & 41 & 68,33 \\
\hline Guaporema & 41 & 68,33 \\
\hline Alto paraíso & 40 & 66,67 \\
\hline Cianorte & 40 & 66,67 \\
\hline Perobal & 40 & 66,67 \\
\hline Esperança nova & 39 & 65,00 \\
\hline Cafezal do Sul & 38 & 63,33 \\
\hline Alto Piquiri & 34 & 56,67 \\
\hline Cidade Gaúcha & 34 & 56,67 \\
\hline São Tomé & 34 & 56,67 \\
\hline São Manoel do Paraná & 33 & 55,00 \\
\hline Cruzeiro do Oeste & 31 & 51,67 \\
\hline Icaraíma & 30 & 50,00 \\
\hline Rondon & 25 & 41,67 \\
\hline Iporã & 16 & 26,67 \\
\hline Ivaté & 7 & 11,67 \\
\hline Média geral & 40,4 & 67,34 \\
\hline
\end{tabular}

Fonte: Dados da pesquisa (2017).

Durante a navegação, foi possível observar que: alguns itens elencados são 
encontrados no mesmo relatório; alguns links são disponibilizados, mas não estão sendo alimentados (através do sistema, são verificadas as abas de pesquisa, porém não existem dados alimentados em todas); dependendo do ente da federação, as transferências (recebidas) podem ser limitadas e alguns entes seguem a orientação da Controladoria Geral da União (CGU, 2013) e utilizam o banner Portal de Transparência e o banner Acesso à Informação para remeter o usuário ao mesmo banco de dados (portal único).

A transparência dos atos e fatos públicos se mostra de várias formas, mas a evidenciação obrigatória, imposta pelas normas legais, faz com que o cidadão tenha o mínimo de informações para melhor fiscalizar os recursos que destina aos órgãos públicos. Não há dúvida de que a LRF foi um marco na história do Brasil, mas a normatização mais eficaz relacionada à transparência pública, visando à promoção da participação popular, iniciou-se a partir de 2005 e teve seu marco legal em 2011 com a LAI, que vem a cada dia proporcionando mudanças culturais nos brasileiros. A transparência e o acesso à informação pública não garantem o correto funcionamento da atividade pública, mas sem eles é improvável que tal atividade ocorra de maneira razoável.

\section{CONSIDERAÇÕES FINAIS}

O presente artigo cumpriu seu objetivo de verificar como está o atendimento às determinações da LAl e da LT, por parte do poder executivo, em municípios com menos de 20.000 habitantes. Por meio das informações analisadas, conclui-se que o Portal da Transparência da maioria das cidades pertencentes à AMERIOS está em funcionamento, entretanto, assim como nos estudos de Pinho (2006), Amaral (2007), Raupp (2014), Costa et al. (2014) e Fabre et al. (2017), não são atendidas todas as exigências legais, proporcionando margem as críticas sobre os elementos da transparência pública.

Em média, são cumpridas $69,34 \%$ das exigências legais por parte dos municípios, sendo que nenhum deles cumpriu a totalidade das obrigações. A falta de fiscalização e de punição podem ser as possíveis causas do não cumprimento integral da legislação.

Hoje há muita informação no portal de transparência, mas a navegação desestimula a busca dos dados. O site oficial deve atrair o cidadão e facilitar seu acesso. A sugestão é a simplificação dos portais para que se tornem objetivos, organizados e o mais transparente possível, pois durante a coleta, várias vezes não foram encontradas as informações na primeira consulta. O acesso fácil leva à 
credibilidade e evita, inclusive, a divulgação de notícias falsas na internet.

Sugere-se ampliar as ferramentas de busca e aprimorar o layout dos portais de maneira a facilitar e estimular as buscas. Os dados gerados pelo sistema poderiam ser baixados em outros formatos de visualização, a fim de gerar gráficos e tabelas de modo organizado, facilitando o entendimento por qualquer cidadão, tendo em vista que o cidadão que não é familiarizado com a nomenclatura da área contábil pública terá dificuldades de navegação.

Um ponto importante a se ressaltar é a autenticidade e a integridade das informações publicadas. Uma das formas de garantir sua veracidade é apresentar a assinatura do responsável. Deste modo, o portal estará de acordo com outro elemento chamado de utilidade de decisão, que está diretamente relacionado com a relevância e a integridade da informação.

Para pesquisas futuras, é necessário verificar o porquê de os órgãos fiscalizadores não estarem autuando os infratores, apurar se existem denúncias ou reclamações sobre a não divulgação das informações, e, principalmente, verificar o que a população acredita ser importante divulgar. $O$ crescimento da transparência pública vai além dos avanços tecnológicos, que a cada dia tem melhorado, pois depende também do estímulo ao cidadão para que este possa consultar, fiscalizar e exigir a divulgação do que Ihe convém, na qualidade de principal agente financiador do governo. A participação social com conhecimento do assunto pode contribuir, significativamente, para uma gestão mais eficiente e transparente.

\section{REFERÊNCIAS}

Abrucio, F. L., \& Loureiro, M. R. (2006). Finanças públicas, democracia e accountability: debate teórico e o caso brasileiro. Rio de Janeiro: Elsevier, 75-108.

Arvate, Paulo R., \& Biderman, Ciro. Economia do setor público no Brasil. Rio de Janeiro: Elsevier, 75-102.

Amaral, M. S. (2007). Accountability, governo local e democracia: investigação em portais municipais do estado da Bahia (Dissertação de Mestrado). Universidade Federal da Bahia, Salvador.

Associação de Municípios de Entre-Rios (AMERIOS). (2017). Recuperado de http://www.ameriospr.com.br.

Barzelay, M. (2001). The new public management. Berkeley: University of California Press.

Brasil. (1988). Constituição da República Federativa do Brasil de 1988. Brasília: 
Senado Federal. Recuperado de http://www.planalto.gov.br/ccivil_03/Constituicao/Consti tuicao.htm.

(2000). Lei de Responsabilidade Fiscal. Lei Complementar $n^{\circ} 101$, de 04 de maio de 2000. Recuperado de http://www.planalto.gov.br/ccivil_03/ leis/lcp/lcp101.htm.

(2009). Lei da Transparência. Lei Complementar n 131, de 27 de maio de 2009. Recuperado de https://www.planalto.gov.br/ccivil_03/leis/ LCP/Lcp131.htm.

(2011). Lei de Acesso à Informação. Lei no. 12.527, de 18 de novembro de 2011. Recuperado de http://www.planalto.gov.br/ccivil_03/_ato20112014/2011/lei/l12527.htm.

Behn, R. D. (1998). O novo paradigma da gestão pública e a busca da accountability democrática. Revista do Serviço Público, 49(4), 05-45. DOI: 10.21874/ rsp.v49i4.399.

Controladoria Geral da União. (2013). Manual de Implantação de Portal da Transparência e Lei de Acesso à informação para estados e município. Cartilha editada pela CGU. Recuperado de https://www.cgu.gov.br/Publicacoes/ transparencia-publica/brasil-transparente/arquivos/manual_lai_estadosmunicipios.pdf.

Costa, A. J. B., Leite, D. B. A., \& Campos, E. S. (2014). Portais de transparência fiscal: uma crítica aos municípios com população entre 50 e 100 mil habitantes. Revista FAE, Curitiba, 17(1), 42-61. Recuperado de https://revistafae. fae.edu/revistafae/article/view/3.

Cruz, C. F., Silva, L. M., \& Santos, R. (2009). Transparência da gestão fiscal: um estudo a partir dos portais eletrônicos dos maiores municípios do Estado do Rio de Janeiro. Revista de Contabilidade, Gestão e Governança. Brasília, DF, 12 (3), 102-115. Recuperado de https://cgg-amg.unb.br/index.php/ contabil/article/view/86.

Denhardt, R. B., \& Denhardt, J. V. (2002). The New Public Service: Serving Rather than Steering. Public Administration Review, 60, 549-559. Doi:10.1111/0033-3352.00117.

Fabre, V. V. (2017). Disclosure Obrigatório Para Portais De Transparência Pública: Um Instrumento De Pesquisa. Revista Livre de Sustentabilidade e Empreendedorismo, 2(2), 218-236. Recuperado de http://www.relise.eco.br/index. php/relise/article/view/95.

Fabre, V.V., \& Bonfante, E. (2018). 10 anos de produção científica sobre Con- 
tabilidade Pública no Brasil. Revista Principia, 1(43), 114-127. DOI: 10.18265/1517-03062015v1n43p114-127.

Fabre, V. V., Bornia, A. C., \& Borgert, A. (2017). Indicador de Disclosure Obrigatório dos Municípios Catarinenses. Anais do ANPCONT, 11. Belo Horizonte.

Fabre, V. V., Rosa, F. S., \& Bornia, A. C. (2016). Disclosure Voluntário do Poder Legislativo das Capitais Brasileiras: Verificando as Ações Praticadas pela Casa do Povo. Anais do ENAPG, 7. São Paulo.

Figueiredo, V. S., \& Gazoni, R. L. (2016). Transparência nos sites dos municípios do Estado do Rio de Janeiro. Revista de Contabilidade e Controladoria, Curitiba, 8(2), 130-143. DOI:10.5380/rcc.v8i2.42996.

Freire, F. R. (2014). Transparência Pública para o Controle Social: um estudo com os usuários do Portal da Transparência do Governo Federal do Brasil. Anais do Congresse Uruguayo de Ciência Política, 5, Montevidéu: Asociación Uruguaya de Ciência Política.

Icerman, R.C., \& Sinason, D.H. (1996). Government accountability to the public: the dynamics of accountability in the U.S. Public Fund Digest, 7(1), 64-80.

Instituto Brasileiro de Geografia e Estatística. (2017). Estados. Recuperado de http://www.ibge.gov.br/estadosat/perfil.php?sigla=pr.

Koppell, J. G. (2005). Pathologies of accountability: ICANN and the challenge of "multiple accountabilities disorder". Public Administration Review, 65(1), 94108. Doi: 10.1111/j.1540-6210.2005.00434.x.

Melo, E. R. P., \& Gomes, A. O. (2016). Proposta de avaliação de portais públicos: aplicação em portais da justiça estadual no Brasil. Universitas Gestão e TI, 6(1), 109-122. Recuperado de https://www.publicacoesacademicas.uniceub. $\mathrm{br} / \mathrm{gti} /$ issue/view/169.

Monteiro, A., Lacerda, M. M., \& Luz, R. S. (2004). A transparência da gestão fiscal na administração pública sob a ótica da sociedade. Monografia de especialização. Universidade Federal da Bahia, Salvador, Brasil.

Mota, A. C. Y. H. A. (2006). Accountability no Brasil: os cidadãos e os seus meios institucionais de controle dos representantes (Tese de Doutorado). Universidade de São Paulo, São Paulo.

Nazário, D. C., Silva, P. F., \& Rover, A. J. (2012). Avaliação da qualidade da informação disponibilizada no portal da transparência do governo federal. Revista Democracia Digital e Governo Eletrônico, 6, 180-199. Recuperado de http://www.egov.ufsc.br/portal/sites/default/files/metricas_do_portal_de_ transparencia.pdf.

Paiva, C. P. R., \& Zuccolotto, R. (2009). Índice de transparência fiscal das contas 
públicas dos municípios obtidos em meios eletrônicos de acesso público. Anais do ENANPAD, 33. São Paulo.

Paludo, A. V. (2010). Administração Pública: teoria e questões. Rio de Janeiro: Elsevier.

Pinho, J. A. G. (2006). Accountability em portais estaduais e municipais no Brasil: realidades distantes das promessas. Anais do ENAPG, 2. Rio de Janeiro: Anpad.

Platt, O. A., Cruz, F., Ensslin, S. R., \& Ensslin, L. (2007). Publicidade e Transparência das Contas Públicas: obrigatoriedade e abrangência desses princípios na administração pública brasileira. Contabilidade Vista \& Revista, 18 (1), 75-94. Recuperado de https://revistas.face.ufmg.br/index.php/ contabilidadevistaerevista/article/view/320.

Prado, O., Ribeiro, M. M., \& Diniz, E. (2012). Governo eletrônico e transparência: olhar crítico sobre os portais do governo federal brasileiro. In Pinho, J. A. G. (Org.). Estado, sociedade e interações digitais: expectativas democráticas. Salvador: EDUFBA, 5-41.

Raupp, F. M. (2014). Procurando transparência, prestação de contas e participação nos portais eletrônicos de câmaras municipais das maiores capitais brasileiras. Revista Iberoamericana de Estudios Municipales, 5(9), 101-121.

Raupp, F. M., Abreu, E., \& Silva, M. S. (2014). Capacidade de prestação de contas dos portais eletrônicos de prefeituras dos maiores municípios brasileiros. Diálogo, 26, 47-60. DOI:10.18316/1520.

Raupp, F. M., \& Pinho, J. A. G. (2013). Accountability em câmaras municipais: uma investigação em portais eletrônicos. Revista de Administração, 48), 770-782. Recuperado de http://www.scielo.br/pdf/rausp/v48n4/11.pdf. . (2014). Prestação de contas nos portais eletrônicos de assembleias legislativas: um estudo após a lei de acesso à informação. Revista Gestão e Planejamento, 15(1), 144-161. Recuperado de https://repositorio.ufba.br/ri/ handle/ri/21969.

. (2016). Review of passive transparency in Brazilian city councils. Revista de Administração, 51(3), 288-298. DOI: 10.1016/j.rausp.2016.02.001.

Rocha, A. C. (2011). Accountability na Administração Pública: Modelos Teóricos e Abordagens. Contabilidade, Gestão e Governança, 14(2), 82-97. Recuperado de https://www.revistacgg.org/contabil/article/view/314/pdf_162.

Souza, S. A., \& Peixe, B. C. S. (2017). Avaliação dos Portais de Transparência 
dos Municípios Paranaenses com mais de 50.000 Habitantes. Anais do Cl$D E S P, 1$. Florianópolis.

Staroscky, E. A., Nunes, G. S. F., Lyrio, M. V. L., \& Lunkes, R. J. (2014). A transparência dos portais municipais sob a perspectiva da legislação brasileira: o caso de prefeituras em Santa Catarina. Reuna, 19(1), 29-52. 